\title{
LA DEMONOMANÍA EN EL ESQUELETO DE UN GIGANTE DE ROBERT MARIE JOHLIO Y PEDRO PABLO VIÑUALES
}

\author{
MBOL NANG \\ École Normale Supérieure \\ Université de Yaoundé 1
}

\section{RESUMEN}

La demonomanía en El Esqueleto de un gigante de Robert Marie Johlio y Pedro Pablo Vinuales analiza la concepción místico-religiosa de la Literatura apoyándose en la antropología, la etnología y la sociocrítica. En la novela el satanismo funciona alegórica, metafórica y metonímicamente como un traje o las malas prendas de vestir de las que los autores quieren despojar a la humanidad entera a través de un pueblo perdido en la selva ecuatorial africana. Después del estudio minucioso de un espacio demoníaco penetrado y regido por los espíritus, después del análisis pormenorizado de algunos temas como las sociedades secretas, la vampirización, la muerte, el culto a los muertos, los espíritus, la adivinación, el totemismo.... se llega a su simbolismo y significado.

Palabras clave: satanismo; novela s. XX; Robert Marie Johlio; Pedro Pablo Viñuales.

\section{RÉSUME}

La démonomanie dans El esqueleto de un gigante de Robert Marie Johlio et Pedro Pablo Viñuales analyse la conception mystique et religieuse de la littérature en s'appuyant sur l'anthropologie, l'ethnologie et la sociocritique. Dans le roman, le satanisme joue de façon allégorique, métaphorique et métonymique comme un costume ou comme les mauvais vêtements dont les auteurs veulent dépouiller toute l'humanité à travers un peuple perdu dans la forêt équatoriale africaine. Après l'étude minutieuse d'un espace démoniaque 
pénétré et gouverné par les esprits, après l'analyse dans tous les détails de certains thèmes tels que les sociétés secrètes, la vampirisation, la mort, le culte des morts. les esprits. la divination, le totémisme. ete., on parvient à découvrir son symbolisme et son sens.

MotS-CLEF: satanisme; roman s. XX; Robert Marie Johlio; Pedro Pablo Viñuales.

Me atrevo a escribir sobre El esqueleto de un gigante a pesar de que exclamara Montaigne (1985: Libro III, cap. XVIII) que existen más libros sobre libros que sobre cualquier cosa. El caso es que en la novela los temas relacionados con el demonio se repiten alegóricamente y llaman la atención. La mentalidad mágica africana en sí es una forma del pensamiento del hombre que no es ni la religiosa, ni la filosófica, ni la científica, ni la artística. Digamos con Julio Caro Baroja (1987: 10) que da la casualidad de que la magia, como constituida por un cuadrilátero, toca por un lado a la religión, por otro lado a la filosofia, por otro ángulo a la ciencia, y por otro lado al arte. Desde luego, podemos, a partir de El esqueleto de un gigante, estudiar la demonomanía como tema literario ya que desde los tiempos más remotos la magia ha interesado al arte: obras tan fabulosas como La Celestina, El Quijote, El caballero de Olmedo, Macheth, el Fausto de Goethe, entran en la temática mágica de la literatura occidental'.

En El esqueleto de un gigante, el espacio textual es un reflejo del mundo y de la cultura bamileké, pero entendiendo reflejo en el sentido lenenista de reflejo sin espejo, esto es, no de manera pasiva, sino como inscripción en el proceso dialéctico de una transformación. Atormenta la idea de un universo vivo en todas partes, preñado de correspondencias ocultas, de ocultas simpatías, penetrado completamente de espíritus, de cráneos de los antepasados; un mundo donde se entrecruzan por todas partes signos de significado oculto difíciles de ser descodificados por no iniciados; donde cada cosa, cada ente y cada fuerza es como una voz aún no oída, una palabra suspendida en el aire; donde cada palabra posee ecos y resonancias innumerales; donde los espíritus se transmiten señales, nos miran y se miran; nos escuchan y se escuchan; donde el universo entero es un inmenso,

\footnotetext{
1 Hay muchas obras y nutridos estudios sobre magia: El Quijote es una reacción ante un mundo mágico en el que él cree y la sociedad en la que él está inscrito; Fray Juan de los Ángeles (1917:56a), en sus consideraciones sobre el Cantar de los cantares, dice que Jeremías compara el mundo y la carne a las lamias que, según el parecer de muchos, son las que nosotros llamamos brujas o hechiceras (latine striges vel sagas) que de noche buscan los niños de teta para chuparles la sangre y matarlos con sus artes malditas; el libro de Fray Jerónimo Mengo (Girolamo Menghi), Flagellum daemonum, además de contener «exorcismos terribles, potentísimos y eficaces» para expulsar de los cuerpos de los obsesos a los espíritus malignos, contiene, antes, un manual del exorcista, basado en muchas autoridades. También del mismo Mengo es el Futis daemonum que contiene unas «adjuraciones formidables y potentísimas» sacadas del «Apocalipsis y varios padres». Allí también hay remedios contra maleficios especiales que producen impotencia, taciturnidad, ligaduras o «ligazones» de todas clases; también podrían citarse el Fasiculus exorcismorum de don Antonio Gasón, el Libro de conjuros contra la tempestad de truenos, granizo, rayos y contra la langosta ... de don Pedro Jiménez, Magia y brujería de Julio Caro Baroja, Sociétés secrètes au Cameroun (Les mystères de la nuit) de Philipppe Laburthe-Tolra, La sorcière de Jules Michelet, Las sociedades maléficas. El diablo, ayer, hoy de Jean-Claude Frère, Magia blanca, magia negra de C. W. Leadbeater, Sorcellerie et politique en Afrique. La Viande des autres de Peter Geschiere, Invención y castigo del brujo en África negra. Teorías sobre la brujería de Aurora González Echevarría. La misma autora (1984:14) nos informa de que los estudios de Tomás (1973) y Macfarlane (1970b) sobre el Essex, influidos por Evans-Pritchard, nos enseñan que el brujo británico es el brujo africano. La creencia del campesino que ve en la vecina a la que no prestó ayuda, en el mendigo, el origen de su mal.
} 
múltiple y variado coloquio, en voz baja o a gritos, enunciado en tonos secretos. $\mathrm{Y}$ en medio de todo ello está el hombre bamileké, ser admirable y mudable, capaz de pronunciar toda palabra, de reproducir cualquier cosa, de proyectar cualquier alfabeto, de responder a cualquier invocación, de invocar cualquier espíritu.

Señaló Julio Caro Baroja (1987: 339-340) que en las obras en las que se discuten problemas relacionados con la magia casi siempre se adopta un criterio de investigación psicológico, sociológico o histórico (cuando no teológico) completamente ajeno a toda inquietud estética. Sin depreciar lo puramente estético en el presente trabajo, insistiré más en lo psicológico y sociológico ya que se trata de ver cómo un ente social reacciona frente a los fenómenos relacionados con lo paranormal, lo sobrenatural, lo metafísico, en breve, con el demonio y sus manifestaciones. La intención moralizadora al tratar de brujería va siempre acompañada de una intención estética a veces humorística. Además las descripciones de escenas místicas que infunden miedo nos conducen directamente a la literatura fantástica aunque tenganos una sensación de realismo literario.

Alreredor del concepto demonomanía giran otros como las sociedades secretas, la brujería, el vampirismo, la adivinación, el totemismo, el culto a los ancestros, las apariciones, lo irracional, etc. En El esqueleto de un gigante, todo ello queda patente en la actuación de los personajes principales, brujos que sólo piensan causar daños a sus víctimas, que se convierten en campeones de ese arte. Están en la conquista de todo el poderío y toda la ciencia que Dios no quiso otorgales en el Jardín de Edén.

Se ve claramente la concepción mística de la literatura, del yo y del mundo que tienen Robert Marie Johlio y Pedro Pablo Viñuales. El deseo permanente de entender una cultura y explicarla se da en la novela como un deseo de salvar la humanidad despojándola de las fuerzas del mal. La demonomanía funcionará metáfora y metonímicamente como un traje o las malas prendas de vestir de que los autores quieren despojar la sociedad bangang.

Para valorar adecuademente el sentido del tema en El esqueleto de un gigante, antes que todo, hay que examinarlo dentro del contexto camerunés, especialmente en el contexto bamileké, y deshacerse de las consideraciones occidentales, aunque a veces haya que recurrir a la bibliografía occidental, a las visiones, a la astrología.

En el presente trabajo no se va a tratar de demonología porque no sería capaz de hacerlo. Soy filólogo y la mezcla de palabras de origen distinto me molesta. Sólo voy a intentar ver cómo el tema del demonio se inserta dentro de la trama narrativa de El esqueleto de un gigante. Este artículo mío, que es puramento erúdito, pretende tener un significado filológico y entrar en la hermenéutica.

\section{El ESPACIO}

El espacio imaginario del relato desde el que los autores intentan involucar en su experiencia al lector, se nos ofrece, así como posibilidad de superación estética e ideológica, al espacio de la brujería, teatro inmóvil en el que los personajes no experimentan la máxima transformación. El espacio novelado se emparenta con el mundo oscuro de la brujería:

Thomas le indicó que la arboleda que quedaba a su derecha, un fragor de sombras recortadas apenas contra las nubes noctumas, era un lugar sagrado donde sólo los iniciados podían entrar. Era 
un cementerio de ajusticiados por brujería. Las mujeres cortaban las raíces próximas al camino por miedo de que, al pisarlas, profanaran aquellos árboles y algo malo les sucediera² (p. 43).

Muchos de los espacios evocados: el altar (p. 35), el corral (p. 36), la cántara de agua (p. 75), el lugar sagrado (p. 50), el pantéon en el que se conservan los cráneos de los muertos (p. 50), la misma naturaleza... tienen algo que ver con los espíritus o con prácticas sagradas u ocultas. La habitación de Ganlekán está llena de horror (97).

No todo es invención evasiva en la novela. En la pintura estilizada de un escenario literario, aparecen realidades muy concretas procedentes de la verdadera geografia del Oeste de Camerún, y que sitúan en un inconfundible marco bamileké la comarca de Bangang. Así pueden verse patios, casas, cementerios, mercados, carreteras, aldeas, arboledas, etc. Ya que se trata de literatura, cada una de las realidades puede no tener connotaciones localizadoras muy concretas, pero en conjunto configuran con bastante fidelidad una geografía fisica y humana específicamente bamileké, y le dan al ambiente un tono «aldeano» muy local que cada nativo de la región reconocería sin dificultad alguna.

Las notas de aldeanismo están reforzadas por la presencia de tipos humanos específicos por su habla, su indumentaria, sus costumbres, la onomástica. Johlio abre espacios en su libro para que la voz del pueblo matice emotivamente lo dicho en lengua extranjera, el español, la lengua del blanco, patrimonio de los privilegiados. La heteroglosia implica pluridad de perspectivas, $y$ de hecho el libro plantea al lector el enfrentamiento de dos culturas, de dos maneras de ver el mundo.

\section{LAS SOCIEDADES SECRETAS}

El universo de la novela de Robert Marie Johlio y Pedro Pablo Viñuales se divide en dos mundos: el mundo natural que todos vemos y contemplamos, y el otro mundo, el de los iniciados, de las castas o sociedades secretas, al ejemplo de la casta chia en la que ingresa Pukum (p. 53):

Los escasos miembros que la componen, de los más temibles, se bastan para comerciar con las almas de los vivos (...). La peculiaridad más increíble de este comercio fatal con lo invisible es que las muertes, de una manera u otra, deben darse dentro de la familia del brujo vendedor, quien está obligado, a intervalos más o menos regulares, a ofrecer una víctima (...)

Todo esto lo sabía, mejor que nadie, el propio Pukum, cuya potencia negativa se extendía como un ala sombría por la aldea, amenazando los secretos círculos de las castas mágicas (pp. 53-54).

Ndé, que goza de autoridad y poderes místicos incontestados, es miembro de dos sociedades secretas: la de los nueve, y la de los siete mandatarios.

Las sociedades secretas que aparecen en El esqueleto de un gigante no son ninguna exclusividad de Bangang, poblado de Camerún donde se desarrolla la trama narrativa. El estudio de Frère Jean-Claude (1982: 21) demuestra que ya existían lo que él llama «las

2 Todas las citas vienen de Robert Marie Johlio y Pedro Pablo Viñuales, El esqueleto de un gigante, Malabo, Ediciones Centro Cultural Hispano-Guineano, s. f. Según los autores, el libro es de 1998. 
primeras sociedades lucíferas medievales». En el examen de las sectas y de las ceremonias que a veces conmueven, horrorizan o asquean, nos vemos obligados a reconocer que no hay en ellas sino la expresión de simples supervivencias culturales primitivas del África tradicional. De hecho nos vemos enfrentados al mundo mágico, con su ordenamiento y con el sentido de sus secretos. Las invocaciones y las fiestas satánicas ponen en movimiento ciertas fuerzas.

\section{LA VAMPIRIZACIÓN}

Es en el tratamiento del tema del vampirismo donde de forma más evidente y clara se muestra la dualidad hombre/espíritu (hombre visible y hombre invisible), la concepción de la vida a través del texto literario, la vida del hombre como un juego de espejos, donde un aspecto de la vida (espejo) se refleja en otro; lo que dificulta la interpretación de los textos al hermeneuta que sólo trabaja con elementos de la lengua. El texto litrario, así, se hace fugaz e inaprehensible como diría Gérard Genette (1970: 7).

La demonomanía en El esqueleto de un gigante se relaciona con lo fabuloso, lo extraordinario, lo sobrenatural. Con rigor casi matemático, Thomas le explica el fenómeno de vampirización a Francisco (pp. 44-45). La vampirización, fenómeno muy difundido en Bangang (p. 44), se percibe en el contexto de la novela como una práctica diabólica y oculta que permite que un individuo abandone su cuerpo fisico para chupar la energía vital de su víctima, quien pierde equilibrio, se vuelve anémica, cansada:

Los espíritus vampiros, que habitan en el sexo de las personas, tienen el poder de salir en la oscuridad para buscar la sangre de la que se alimentan (p. 44$)^{3}$.

\footnotetext{
'Aurora González Echevarría (1984: 59-60), citando a Mallart, da la siguiente información: «En el origen Dios creó cuatro humanos, el hombre, el gorila, el chimpancé y el evú. Después creó tres mujeres y se marchó. Antes de partir le dio una mujer al hombre, otra al gorila, y otra al chimpancé. Al evú no le dio mujer. Del mismo modo repartió las riquezas entre los tres primeros seres sin darle nada al evú. Sólo el tronco del árbol aban como morada.

Después de que el hombre se separara a causa del fuego de sus hermanos, el gorilla y el chimpancé, la mujer del hombre quedó encinta. Su marido fue a la selva, a buscar a sus hermanos el gorila y el chimpancé. Antes de dejar a su mujer le proporcionó el agua, la leña y los víveres que iba a necesitar durante su ausencia y le pidió que cuidase al niño, que no abandonase la choza, y que no se acercara al árbol donde moraba el evú. Durante la ausencia del hombre, la mujer dio a luz.

La mujer, dominada por la curiosidad, se acercó al árbol aban e invitó al evú a acompañarle al poblado. El evú se negó. La mujer insistió, hasta que el evú estuvo de acuerdo. Quiso transportarlo sobre sus hombros, pero el evú se negó. Quería ir en el vientre de la mujer. La mujer se sentó y el evú penetró en su vagina, ajustando su cuerpo al de la mujer, de modo que su cabeza ocupaba la de la mujer, sus brazos penetraron los de la mujer, hasta que el ajuste fue total.

Cuando llegaron al poblado, la mujer le pidió al evú que saliese pero éste se negó: quería permanecer en el cuerpo de la mujer, como estaba en el interior del árbol. Cuando tuvo hambre no quiso comer los alimentos que la mujer le cocía. Pidió sangre. La mujer le trajo primero los volátiles del marido, después los perros, por fin las cabras: cuando lo hubo comido todo, mordio el vientre de la mujer para advertirle que quería comer a su hijo. La mujer le dio al niño.

Cuando volvió el marido, invocó a Dios desesperado, y le pidió u: remedio para hacer salir al evú del vientre de su esposa. Dios dijo que el evú quedaría con la mujer para siempre, pero que podía darle otra mujer y otra tierra. El hombre no aceptó la propuesta de Dios porque ya estaba acostumbrado a su mujer y no podría vivir con otra. El hombre fecundó a la mujer que dio a luz a los ancestros cuyos descendientes pueblan el centro de la selva ecuatorial».
} 
Se puede, incluso, chupar la sangre de los propios familiares. Es el caso de Pukum que piensa de ese modo alargar su vida. No vacila en «sacrificar» a sus tres hijos de 2, 4 y 5 años. Declara:

Los que la gente llama hijos de mis mujeres son en realidad mis hijos. Ninguna de las siete esposas que tengo vino a mi casa cogiendo a un niño de la mano. Yo les créé y su vida a mí me incumbe (p. 56).

El bangangués ve en el espíritu vampiro una sustancia ultraespiritual, una fuerza vital, la base de la fe en la prolongación de la vida a través de la absorción de sangre aje$\mathrm{na}^{4}$. No sólo se bebe sangre sino que se come. La cántara encantada de Meniolecua mostró a Pukum comiendo los sesos de su hija (p. 86). Un niño reveló a la mujer que acababa de darle de comer que «había oído comentar que los vampiros pensaban comérsela esta misma noche»(p. 45) y le recomendó que se quedara velando toda la noche, con una olla abierta sobre la hoguera. Cuando oyera algunos ruidos estraños en ella, significaría que los vampiros habían llegado, por lo que no tendría que taparla para tenerlos encerrados.

Para protegerse de las acciones demoníacas de los vampiros, se necesitan los blindajes de los curanderos (p. 55), práctica aceptada incluso por algunos intelectuales africanos $^{5}$.

Todas esas prácticas, según Martín Walker (1993: 21), no tienden sino a infundir miedo, es decir miedo a «dejar de ser», una falta de conformidad que impulsa al ser humano a rebelarse contra el destino fatal, pretendiendo con el rechazo a la muerte preservar su individualidad.

\section{LA MUERTE}

La muerte es, claro, algo natural. Pero en la novela de Robert Marie Johlio y Pedro Pablo Viñuales, viene siempre de la mano ajena. Es la consecuencia lógica, el resultado de las prácticas demoníacas de Ganlekán o Pukum (p. 55). La sucesión de fallecimientos en una familia, las muertes repentinas e inexplicables entran en el laberinto de una mentalidad bangang que más cree en el satanismo que en la muerte natural:

¡Cómo va cambiando este pueblo (...) y cambia negativamente! Antes crecíamos junto a nuestros bisabuelos. Antes la muerte venía como algo natural y era un descanso. Pero estas muertes de niños tiernos y por razones tan turbias se hacen inadmisibles (p. 61) .

\footnotetext{
${ }^{4}$ No es nada nuevo. Frère Jean-Claude (1982: 41) nos informa de que Gilles de Rais, maréchal de France a los 26 años, abominable glorioso compañero de Jeanne d'Arc, hacía matar y mataba a niños para recoger su sangre y escribir un gran libro mágico con la sangre de sus víctimas. Terminado ese libro, estaría investido de tal poder mágico que con un solo gesto podría apoderarse de todas las fortalezas del país.

${ }^{5}$ Jean Sakou declara: «La puissance du support matériel dépend de la provenance et de la nature de l'objet. (...) la force réside dans les vibrations qu'il émet et qui nécessairement doivent renforcer celles de l'utilisateur afin de devenir une source de protection contre les vibrations maléfiques émises par le sorcier», en «Peut-on se protéger contre le sorcierm, Multi SAT-TV n..$^{\circ}$ 51, Sept. 1999, p. 14.

${ }^{6}$ El subrayado es mío.
} 
Consecuencia inmediata del vampirismo, la muerte amenaza a la sociedad e inquieta. Encuentra su explicación y sentido en lo irracional ya que generalmente no encuentra ninguna causa natural. Supone casi siempre el quebrantamiento del orden cósmico. Es la actuación de un ser inteligente, un espíritu del mal, ya sea una persona en la tierra o una del otro mundo. La muerte súbita de Demanú (p. 40) no puede ser nada natural, sino el resultado del vampirismo ambiente de Bangang. Se piensa que el hechicero asesino de Pukum puede transformase en alacrán o en serpiente (p. 87) 7 .

El Bamileké ve continuamente sobre sí espíritus a su favor y espíritus en contra suya $^{8}$. De aquí su psicología de hombre colocado entre dos fuegos, combatido por unos y defendido por otros. Unas veces en la euforia del que se siente omnipotente con los espíritus favorables y otras en la depresión de quien se siente derrotado por tantos enemigos. Cuando un enfermo recupera la salud, se dice que vence el espíritu bueno, y cuando muere, gana la batalla el espíritu malo.

\section{El CULTO A LOS MUERTOS}

El bangangués del libro de Johlio cree en el más allá, mundo habitado por los antepasados muertos del clan. Por ello se exhuman y se conservan sus cráneos, objetos de culto, en lugares sagrados. Son los protectores de los vivos. La hacienda de Ndé,

Como todas las haciendas de su importancia, (...) tenía también su lugar sagrado, su pequeña choza detrás de la vivienda, el pantéon en el que conservamos los cráneos de los muertos familiares quienes aún no acabamos de adoptar otras costumbres extrañas. Aquí venía Ndé para agradecer sus riquezas y solicitar de los ancestros, con aceite, carne de cabra y sal, como se debe, la necesaria protección de sus hijos (p. 50)9

La creencia más generalizada es que los antepasados sirven de vínculo, de intermediarios, entre la familia y el más allá. De ahí el culto a los muertos. Dios está tan lejos que hace falta pasar por los antepasados. Y los muertos poseen una fuerza extraordinaria, pueden hacer lo que quieran; por lo tanto hace falta mendigar sus favores.

Los cráneos humanos, los ramos, los rabos de caballo, las pieles de pantera, las coronas y las guirnaldas ${ }^{10}$, lo oscuro y lo lúgubre, como es sabido, han tenido y siguen te-

7 También existe este tipo de muerte en Francia en el Bocage, en Inglaterra, en Méjico, en África... Aurora González Echevarría (1984: 27) dice que también hay brujos en África. Los hay desde hace mucho tiempo y los seguía habiendo en Camerún en 1978, cuando una de las esposas de un curandero basá, ella misma enferma y al poco tiempo de perder un hijo, me decía, sentada a mi lado durante una sesión terapéutica que realizaba su esposo: «No sé en otros lugares, pero entre nosotros, es la brujería lo que nos enferma y lo que nos mata».

${ }^{8}$ Para más informaciones sobre la creencia en los espíritus en África, véase A. Martín del Molino (1989: 183).

${ }^{9}$ Paul Reader (1994: 13) se burla de los que creen que un pedazo de serpiente se agita y parece vivir separado del cuerpo, como le ocurre al rabo de una lagartija; no hay duda de que el hueso del león tiene propiedades de valor; un trozo de cráneo otorga las propiedades del muerto.

10 Javier Salazar Rincón (1999: 496) afirma que la corona, por su forma circular, es un conocido símbolo solar, y colocada sobre la cabeza, la parte más elevada del cuerpo, sitúa a quien la ciñe en contacto con el reino celestial; $y$, en fin, por ser las plantas de las que están hechas las guimaldas y coronas, los atributos de ciertos dioses de la Antigüedad - el laurel de Apolo, el olivo de Minerva, el mirto de Venús, etc.—, su posesión asimila a quien las lleva con la divinidad correspondiente, permitiéndole participar, aunque sea de una manera vicaria, de su poder y superioridad. 
niendo un papel importante en el pueblo bamileké en ritos diabólicos, exorcismos, ciencias ocultas, sociedades secretas, ritos funerarios. Son el símbolo de la permanencia del difunto, la esperanza, la gloria, la consecución del poder místico y la inmortalidad.

Según C. W. Leadbeater (1992: 19), otro punto que no se debe olvidar es que estamos rodeados de todos aquellos que llamamos muertos; es decir, de todos aquellos que sólo han abandonado recientemente sus cuerpos físicos, y que todavía revolotean en torno nuestro en sus vehículos astrales. Éstos también pueden ser influidos, bien sea mesméricamente o por la pasión, del mismo modo que los que todavía están encarnados; y son en verdad muchos los casos en que debemos contar con su acción, así como comprender hasta qué punto se puede utilizar su dominio de las fuerzas astrales.

\section{LOS ESPÍRITUS}

El tratamiento del tema del vampirismo, otra de las grandes obsesiones de la novela, entra en la dualidad hombre-espíritu, conectando, asimismo, directamente con consideraciones místico-religiosas, creencias populares bamileké, ciencias ocultas. Parece como si el problema se les presentara a los autores de manera inquietante, o fuera percibido por ellos en momentos de comunión con el cosmos. El libro nos introduce en el mundo místico de los seres extraños de Bangang, generalemente espíritus, que pueden enfadarse del mal comportaniento de los humanos:

Hijos míos (...), benditos seáis por haberme encontrado. Soy el espíritu guardián de la selva y el protector de vuestro pueblo (...). Dejad, niños, el asunto del fuego e id a comunicar a vuestros parientes que sólo el respeto de las tradiciones impedirá que la muerte extienda su inmensa manta negra sobre el pueblo. Decidles que no podrán alcanzar la paz sin la virtud. He dicho. (p. 59).

La creencia en los espíritus conlleva otra: la fe en los fetiches, árboles sagrados, piedras sagradas, grutas, bosquecillos, entidades dotadas de fuerzas sobrehumanas que pueden ser positivas o negativas, los cráneos de los ancestros. Consiguientemente hay que darles de comer para evitar su ira.

El esqueleto de un gigante reboza de una pluridad de dioses y espíritus. Fobim es el Dios de la Selva (p. 68), los «espíritus de los antepasados» (pp. 59 y 75) protegen y son muy generosos con la tribu. Basta con dirigirles oraciones para conseguir cualquier cosa. A. Martín del Molino (1989: 79) dice que los espíritus tienen el poder de trasladarse con gran velocidad de un lugar a otro y, sobre todo, el poder de transportar por los aires a los hombres vinculados a ellos. Un hombre poseído por los espíritus no necesita atravesar por su pie un río: podrá cruzarlo de un salto, pues el espíritu le levantará y le trasladará a la otra orilla. Ahora bien, aunque Dzeusse, la curandera, ostenta la autoridad científica que le concede la tribu para practicar su actividad sanadora (p. 34), nos enteramos de que los contactos entre los vivos y los espíritus se hacen mediante curanderos y curanderas que distan muy poco de los brujos endemoniados: 
La curandera le aclaró ( $a$ Francisco), como si eso lo explicara todo, que en ningún momento era ella quien podía sanar, ni predecir, ni adivinar, sino que eran los espíritus quienes lo hacían a través suyo (p. 35)".

Los espíritus no debieron comunicarle nada bueno, porque a la vieja se le frunció el ceño y por un instante su rostro sereno se empañó. (p. 36).

\section{LA ADIVINACIÓN}

Los personajes de El esqueleto de un gigante representan varios mundos, entre ellos el de los espíritus que nunca han encarnado: es el mundo de Ganlekán; el mundo de los fallecidos: es el mundo de los ancestros; el mundo de los vivos. Algunos vivos tienen el poder de comunicar con el más allá mediante la adivinación, procedimiento que tiene como meta la búsqueda de las causas de las enfermedades, de las muertes en serie en una familia, de acontecimientos sobrenaturales.

La adivinación es llevada a cabo en la novela por Dzeusse y Meniolecua, dos mujeres con dotes sobrenaturales que les permiten ver con ojos inmateriales cosas pasadas, presentes, venideras u ocultas ya que tienen la facultad neumática de comunicar con los antepasados (pp. 35; 100). Para entrar en el cosmos invisible, se sirven del agua (pp. 7576), del polvo, de la tierra de la suela de los zapatos, etc. A Meniolecua, por ejemplo, la llaman la «Señora Dios» (p. 82).

Cabe precisar que, por las invocaciones, los videntes se ponen en contacto con los espíritus desencarnados del cosmos, procedimiento que les permite meterse en la misma longitud y facilitar que bajen los espíritus ya que

en ningún momento era ella (la vidente) quien podía sanar, ni predecir, ni adivinar, sino que eran los espíritus quienes lo hacían a través suyo (p. 35).

Las escenas de adivinación están envueltas en escenas místicas y se celebran en lugares dichos sagrados (p. 35). Muere súbitamente Demanú, una de las esposas del terrible y temido Ganlekán. Pero su muerte ya la había visto Dzeusse mirando en una tinaja hundida en el seno de la tierra.

${ }^{11}$ C. W. Leadbeater (1992) afirma que existe un reino lleno de vida que no pertenece a nuestra línea de evolución humana, pero que al parecer corre paralelo con ella (p. 14) (...) aquellos sólo poseen cuerpos astrales (p. 15) poseen ciertos poderes y métodos peculiares suyos (p. 16) (...) pueden ser fácilmente dominados por medio del ejército de los poderes mesméricos, y ser utilizados de muchas maneras para transmitir la voluntad del mago (pp. 16-17). Existen muchos fines para los cuales pueden ser empleados, y mientras que la tarea que se les encomienda esté dentro de sus posibilidades, será fiel y escrupulosamente ejecutada. Advierte el mismo autor: "Yo mismo he hecho un estudio bastante detenido de este asunto, y espero que me dispensaréis si hablo de manera afirmativa y como de hechos reales y positivos, acerca de muchas cosas que para la mayoría de vosotros podrán parecer dudosas o que están por encima del conocimiento humano" (p. 17).

En el caso concreto de Camerún y principalmente de la sociedad bamileké que estudiamos, es una creencia generalizada que la mayoría de los espíritus tienen su centro de operaciones en el Pico de Mont Koupé. Se trata de los espíritus de los duendes. Se dividen en dos clases: los espíritus buenos y fecundos que respetan las casas de los poblados, y los malos y devastadores, maléficos, autores de los males y daños del hombre, destruyen las cosechas. 
Encontramos poderes adivinos en los personajes de El esqueleto de un gigante y adivinos encontramos en la literatura clásica ${ }^{12}$. Con todo, hay que reconocer que el libro se inscribe en un ambiente de magia y astrología universal en el que, como luminosamente ha mostrado Garín (1981: 203), se expande «la idea de un universo vivo en todas partes preñado de correspondencias ocultas (...), donde los astros nos transmiten señales y se las transmiten entre sí...”

El mundo está revuelto. Se paraliza el tiempo y, así, pasado, presente y futuro se confunden.

Digamos para resumir que en la novela la adivinación ${ }^{13}$ es llevada a cabo por la mujer, sacerdotisa que controla una gran candidad de cultos privados y ocultos. Esa misión religiosa de la mujer está relacionada casi siempre con las divinidades bamileké y con la idea de dominar el tiempo y, por consiguiente, el porvenir de los hombres. Sus actividades nocturnas suelen tener en general un carácter misterioso, más herméticas que las diurnas. En una palabra, la mujer está asociada a ritos nocturnos, a las divinidades de la noche, a lo secreto. En la novela aparece dominando al hombre por medio de la adivinación. En relación con esto se le tiene miedo ya que está idealizada y divinizada.

\section{EL TOTEMISMO}

La demonomanía se manifiesta también en El esqueleto de un gigante por el totemismo. El tótem, que puede ser un animal, un pájaro o un árbol, se concibe en la mitología bamileké como el emblema protector de su doble físico, o de la tribu, y a veces como ascendiente o progenitor, el doble de la persona en el plano físico. En virtud de fuerzas ocultas no explicables cartesianamente, el tótem asume la forma específica del cuerpo al que está ligado.

En la novela algunos hombres tienen el poder de transmitir parte de su cuerpo anímico a animales por procedimientos ocultos. Uno de los casos es la experiencia vivida por el joven cazador Foti, quien sale de su poblado a la aldea vecina donde llega de noche con la intención de cazar al elefante grande de la selva. Ahí en Tamechio le hospeda un viejo canoso. Muy temprano, armado de su lanza, Foti integra la jungla. Apunta al animal que desaparece al igual que su lanza. Foti cae inconsciente y recobra sus sentidos al cuarto día. De regreso al pueblo,

encontró, sobre la estera en que había dormido, su desaparecida lanza (p. 63).

12 Lucano, en La Farsalia, nos presenta a Fígulo, quien predice las guerras civiles que asolarán a Roma y la posterior tiranía de César. Enareto, famoso personaje de Sannazaro, es un profundo conocedor de la magia. En la Egloga II, Garcilaso sigue una técnica aprendida de Virgilio. La capa profética del río Tormes se inspira en la profecía que el río Tíber hace a Eneas sobre el futuro de sus trabajos, y de su hijo, en Italia. En un pasaje de De partu Virginis de Sannazaro, el río Jordán adquiere cualidades proféticas. En la Egloga II de Garcilaso, el Danubio anima a Carlos $\mathrm{V}$ y a don Fernando, duque de Alba, a lanzarse sobre los turcos, como el Tíber, en el libro VIII de la Eneida, anima a Eneas a enfrentarse con su futuro itálico.

13 La adivinación es un fenómeno generalizado en África. Según Aurora González Echevarría (1984: 40), los mundang son una de las principales etnias del Chad. Llaman la adivinación Kindani, palabra que denota el bastón o caña con los que un muchacho guiaba a un hombre ciego. 
La desaparición de la lanza y del elefante conduce a otra de tantas manifestationes del satanismo de que reboza el cuento: el totemismo, al juego de espejos: cualquier conocedor de la cultura bangang deducirá que el elefante percebido por Foti no era sino el tótem, el doble espiritual del anciano canoso quien, rotundamente, advierte:

¡Cuidado! No todos los animales son iguales. Entre ellos, en ocasiones, hay seres humanos especiales (p. 64).

En su combate místico contra Dzeusse, Ganlekán se desdobló y un enorme cuervo vino a posarse sobre la ventana (p. 100).

¿Cómo relacionar científicamente el talar un árbol y la muerte de su proprietario

(...) ese árbol suyo fue talado en la selva próxima. Y, como por extraños vínculos siempre ignorados, aquella misma tarde su padre murió (p. 52).

sino deducir sencillamente que en el árbol vivía el doble espiritual de ese señor? Concluyamos diciendo con el Padre Hebga que

des savants ont mis en évidence, en laboratoire, le fait que certaines personnes peuvent matérialiser, à partir de leur propre organisme et d'organismes environnants, des formes vivantes animales ou autres (...) il s'agit d'ectoplasmes formes animales ou humaines à base d'une matière sensible aux confins de l'esprit.

El totemismo va relacionado siempre con lo irracional.

\section{CONCLUSIÓN}

Umberto Eco en sus Apostillas a El hombre de la rosa (1984: 40) dice:

Tanto Joyce como Eliot me habían enseñado que el arte es la huida de la emoción personal.

Y mucha emoción personal hay en las páginas de El esqueleto de un gigante. Es difícil sacar una conclusión sobre la demonomanía en la novela a no ser uno de la materia. No podemos ir más allá de la simple explicación literaria del fenómeno: los mecanismos secretos del satanismo bamileké, que arrancan de una larga tradición, se nos escapan. La parte irracional y misteriosa es inmensa. Hemos intentado comprender las actuaciones del hombre en sí, independientemente del mundo sobrenatural que le envuelve y le atemoriza. Ese hombre desciende hasta las raíces de la existencia humana, hasta las fuerzas escondidas del universo en busca de maravillas. Entonces se encuentra en contacto inmediato con lo satánico que a veces se torna contra él si no lo vence. La mística satánica penetra en un mundo subterráneo para legitimarlo, desafiar a los no iniciados. Y es así como algunos se entregan a la obesión satánica y buscan acrecentar su poder, su riqueza y ocupar un sitio de honor en la sociedad bangang (Ganlekán). 
La novela enlaza de vez en cuando sus hilos argumentales y narratológicos con los de la realidad social bamileké para adoptar la apariencia de una realidad histórica. Pasajes enteros iluminan facetas del estado mental y estético de Johlio, incluso su concepción de sí mismo, del arte africano, de las tradiciones, especialmente de la brujería. Existen en el texto claras referencias a la floreciente tradición camerunesa actual. Ello evidencia la larga historia del pueblo bamileké.

Sólo diría que el satanismo en el libro de Robert Marie Johlio y Pedro Pablo Viñuales se confunde con la vida del bamileké, sus creencias y sus ideas. Las historias de brujos espantan tanto como los relatos fantásticos. Es como si uno estuviera dentro del laberinto - esta vez oscuro y sin salida - de Jorge Luis Borges. El universo de los brujos es un mundo de símbolos ocultos y de fuerzas que sólo se manifiestan a partir de un conocimiento simbólico del universo que podría llamarse satanismo, magia.

La magia, el exorcismo, el culto al diablo o la erotología de Satán son hechos que aún hoy, en el siglo de la epopeya humana hacia la luna, en los años de los transplantes de corazones y riñones, conservan sus adeptos como en plena Edad Media o en el S. XVIII, los periodos más álgidos de la brujería.

Podría preguntarse si los autores de El esqueleto de un gigante condenan la cultura y las costumbres bamileké. Más que de una condena, creo que se trata de un afán de entender y explicar esa cultura. Robert Marie Johlio, depositario de esa cultura, no se atrevería a condenarla. Pedro Pablo Viñuales, que no entiende nada de ella, tampoco se atrevería. Acaso haya aquí una condena sútil pero se pretende sobre todo compensar los aspectos morales y humanitarios que se critican en la obra. Johlio, pues, presenta un programa doble para la juventud que debería saber seleccionar dentro del amplio abanico de valores de la cultura bamileké, lo bueno y lo malo. La obra, en este sentido, tiene un valor altamente didáctico. Para conseguir ese objetivo, Johlio elige de la realidad aquellas sustancias y nociones que denotan o connotan no lo aristocrático, refinado y bello, sino lo vulgar, grotesco y feo. El enfoque de Robert Marie Johlio es como una piedra tirada al agua con que se van formando ondas concéntricas que se amplian hasta muy lejos del punto de impacto.

\section{BiBLIOGRAFIA}

ÁnGELES, Fray Juan de los (1917): Obras místicas del M.R.P Fray Juan de los Ángeles, Madrid, s.f.

Parte segunda «Nueva biblioteca de autores españoles», XXIV.

Caro Baroja, Julio (1987): Magia y brujería, San Sebastián, Ed. Txetoa.

Eco, Umberto (1984): El hombre de la Rosa, Barcerlona, Lumen.

FRÈRE, Jean-Claude (1982): Las sociedades maléficas. El diablo, ayer y hoy, Barcelona, Ediciones Martínez Roca.

GARIN, E. (1981): La Revolución cultural del Renacimiento, Barcelona, Crítica.

GENETTE, Gérard (1970): Figuras. Retórica y estructuralismo, Córdoba (Argentina), Ediciones Nagelkop. La edición original es de París, Seuil, 1966.

GONZÁLEZ ECHEVARRÍA, Aurora (1984): Invención y castigo del brujo en el África negra. Teorías sobre la brujería, Barcelona, Ediciones del Serbal.

HeBga, Meinrad P. (1979): Sorcellerie, chimère dangereuse, Abidjan, INADES,

LABURTHE-Tolra, Philippe (1985): Sociétés secrètes au Cameroun (Les mystères de la nuit), París, Karthala. 
LEAdBEATER, C. W. (1992): Magia blanca magia negra, Sevilla, Muñoz Moya y Montraveta, editores.

Martín del Molino, Amador (1989): Los bubi. Ritos y creencias, Malabo, Centro Cultural Hispano-Guineano.

MiChelet, Jules (1863): La sorcière, Bruselas y Leipzig, A La Croix, Verboeckhoven et Ce, éditeurs.

MONTAIGne (1985): Ensayos, Madrid, Catedra.

ReAder, Paul (1994): Magia Negra y hechicerías, Barcelona, Senba Ediciones.

SALAZAR Rincon, Javier (1999): «Ramos, Coronas, Guirnaldas. Símbolos de amor y muerte en la obra de Federico García Lorca», Revista de literatura, tomo LXI, núm. 122, julio-diciembre 1999, pp. 495-519.

WALKER, Martín (1993): El misterio de los vampiros, Barcelona, Edicomunicación. 